\section{Analisis Perubahan Garis Pantai Berdasarkan Data Citra Satelit di Wilayah Pesisir Kota Makassar Provinsi Sulawesi Selatan}

\author{
Usman', Muhammad Azis Irbani \\ Universitas Negeri Makassar ${ }^{1,2}$
}

Email: usman7004@gmail.com

Abstrak. Penelitian ini bertujuan untuk menganalisa perubahan garis pantai di Pesisir Kota Makassar dengan menggunakan metode Digital Shoreline Analysis System (DSAS). Data yang digunakan dalam penelitian ini adalah data sekunder berupa data citra digital satelit Landsat 5 dan Landsat 8 yang diakuisisi tanggal 8 April 2019 dan telah terkoreksi radiometrik dan geometrik diperoleh dari Lembaga Penerbangan dan Antariksa Nasional (LAPAN). Data tersebut diolah dengan menggunakan software ArcGIS 10.3 untuk memperoleh hasil Overlay. Metode perhitungan perubahan garis pantai yang digunakan pada DSAS yaitu metode Net Shoreline Movement (NSM) dan End Point Rate (EPR). Pengamatan perubahan garis pantai mengambil rentan waktu 12 tahun menggunakan data tahun 2006, 2010, 2013 dan 2018. Berdasarkan hasil analisis dengan metode Digital Shoreline Analysis System (DSAS) selama kurun 12 tahun pesisir Kota Makassar mengalami perubahan garis pantai yaitu akresi akibat reklamasi yang terjadi pada Kecematan Tallo dan Kecematan Tamalate.

Kata Kunci: DSAS, Garis Pantai, Landsat 5, Landsat 8.

\section{INDONESIAN JOURNAL OF FUNDAMENTAL SCIENCES (IJFS)}

\section{E-ISSN: 2621-6728 \\ P-ISSN: 2621-671X}

Submitted: July, $7^{\text {th }} 2019$

Accepted : August, $27^{\text {th }} 2019$

Abstract. This study aims to analyze the changes in the coastline in the coastal of Makassar city by using Digital Shoreline Analysis System (DSAS) method. The data used in this study was secondary data in the form of Landsat 5 and Landsat 8 digital satellite data which were acquired on 8 April 2019 and have been corrected radiometrically and geometrically obtained from the Lembaga Penerbangan dan Antariksa Nasional (LAPAN). The data was processed using ArCGIS 10.3 to obtain the overlay result. Shoreline Movement (NSM) and End Point Rate (EPR) methods used to calculate shoreline change calculations. Observation of shoreline changes takes 12 years using data in 2006, 2010, 2013, and 2018. Based on the results of the analysis with the method of Digital Shoreline Analysis System (DSAS) found that during 12 years the coast of Makassar experienced a change in coastline which is accretion due to reclamation that occurred in Tallo and Tamalate sub-districts. 


\section{PENDAHULUAN}

Garis pantai merupakan garis pertemuan antara daratan dengan lautan yang dipengaruhi oleh pasang surut air laut. Garis pantai juga selalu berubah dengan sangat dinamis dan saling berinteraksi dalam merespon dampak dari proses dinamika oseanografi maupun aktivitas manusia di sekitar kawasan pantai. Kemampuan pantai tersebut merupakan respon alami pantai terhadap laut sehingga pantai memiliki kawasan yang selalu mengalami perubahan profil pantai, ini terjadi secara cepat ataupun lambat tergantung pada imbang daya antara topografi pantai, proses hidro-oseanografi, partikel sedimen yang masuk maupun meninggalkan pantai serta aktivitas manusia di sekitar kawasan pantai.

Garis pantai selalu mengalami perubahan posisi yang berlangsung secara terusmenerus, perubahan ini akibat proses pengikisan daratan yang biasa disebut abrasi maupun penambahan daratan yang disebut akresi. Pada dasarnya proses perubahan pantai meliputi proses erosi dan akresi. Erosi pada sekitar pantai dapat terjadi apabila angkutan sediment yang keluar ataupun yang pindah meninggalkan suatu daerah lebih besar dibandingkan dengan agkutan sediment yang masuk, apabila terjadi sebaliknya maka yang terjadi adalah sedimentasi (Triatmodjo, 2011).

Dalam melakukan pemantauan perubahan garis pantai dapat digunakan teknologi pengindaraan jarak jauh dan Sistem Informasi Geografis (GIS). Dalam pemanfaatan teknologi ini sangat diperlukan untuk memantau perubahan garis pantai terutama pada daerah yang memiliki panjang garis pantai yang luas atau wilayah yang memiliki banyak pulau seperti pulau-pulau di Indonesia (Winarso dkk, 2001). Metode untuk mengetahui jarak perubahan garis pantai yaitu dengan menggunakan Digital Shorline Anlysis System (DSAS). DSAS merupakan perangkat lunak yang dapat digunakan untuk mengetahui laju perubahan garis pantai dari waktu ke waktu (Hakim dkk, 2014).

Dewi, dkk (2017) melaksanakan penelitian tentang Analisis laju perubahan garis pantai Pulau Karimun Besar menggunakan Digital Shorline Anlysis System (DSAS). Tujuan penelitian tersebut yakni untuk mengidentifikasi dan memperkirakan laju perubahan garis pantai yang terjadi di Pulau Karimun Besar. Penelitian ini dilakukan untuk menganalisis perubahan garis pantai berdasarkan data pengindraan jauh (satelit) yang diperoses oleh GIS (Geografis Informasi Sistem). Kemudian, untuk menganalisis perubahan garis pantai menggunakan DSAS (Digital Shorline Analisis Sistem) dengan metode statistik LLR (Linear Regression Rate). Hasilnya ditemukan garis pantai telah berubah selama 25 tahun (1991-2016) dengan abrasi 1,63 meter/tahun dan akresi 3,78 meter/tahun.

\section{METODE PENELITIAN}

Pengumpulan data yang dilakukan dalam penelitian ini yaitu data lapangan dan data sekunder dari Lembaga Penerbangan dan Antariksa Nasional (LAPAN) Parepare. Data lapangan didapatkan dengan mendatangi lapangan secara langsung kemudian didapatkan koordinat lokasi penelitian serta kondisi lokasi penelitian. Data sekunder didapatkan dengan mengirim surat izin penelitian di Lembaga Penerbangan dan Antariksa Nasional (LAPAN) Parepare. Metode yang digunakan dalam analisis data adalah metode penelitian terapan. Penelitian ini dilakukan di 
Kota Makassar provinsi Sulawesi Selatan berkoordinat di $119^{\circ} 18^{\prime} 27,97^{\prime \prime}$ sampai $119^{\circ}$ 32' 31,03" BT dan $5^{\circ} 30^{\prime} 18^{\prime \prime}$ sampai $5^{\circ} 14^{\prime} 49^{\prime \prime}$ LS. Data yang digunakan dalam penelitian ini yaitu data garis pantai tahun 2006, 2010, 2013 dan 2018 yang bersumber dari LAPAN Parepare sebagai berikut :

Tabel 1. Sumber Data Citra Satelit

\begin{tabular}{cccc}
\hline No & Citra satelit & Tanggal & Jenis Sensor \\
\hline 1 & LT05_L1TP_114064_2006 & 29/07/2006 & Thematic Mapper (TM) \\
& 0729_20161120_01_T1 & & \\
2 & LT05_L1TP_114064_2010 & 24/07/2010 & Thematic Mapper (TM) \\
& 0724_20161014_01_T1 & & Operational Land \\
3 & L8OL_114_064_20131020 & 20/10/2013 & $\begin{array}{c}\text { Imager (OLI) } \\
4\end{array}$ \\
& LC08_L1TP_L1T_001 & & Operational Land \\
& 0714_20180714_01 & 14/07/2018 & Imager (OLI) \\
\hline
\end{tabular}

Pengambilan data secara langsung dilakukan pada daerah Kecamatan Biringkanaya, Kecematan Tamalanrea, Kecamatan Tallo, Kecamatan Ujung Tanah, Kecamatan Wajo, Kecamatan Ujung Pandang, Kecematan Mariso dan Kecamatan Tamalate. Survei Lapangan dilaksanakan pada tanggal 29-31 juli 2019 untuk melihat secara langsung kondisi lapangan dan mengambil titik koordinat setiap lokasi pengambilan data menggunakan GPS (Global Position System). Adapun alat dan bahan yang diperlukan untuk penelitian ini yakni Alat tulis menulis, Smartphone, Seperangkat Laptop/PC, Microsoft Office 2013, Software ArcGIS 10.3, Software ENVI 5.1, Peta RBI 1:50.000 dan data citra satelit pada tabel 1.

Metode yang digunakan untuk menganalisis data ini dengan menggunakan Digital Shoreline Analisis Sistem (DSAS). Proses pengolahan data citra satelit diawali dengan menggunakan software ENVI 5.1 untuk membagi klasifikasi daratan dan lautan. Proses ini nantinya akan memotong data citra yang ingin diinterpretasi agar memperoleh wilayah fokus penilitian saja. Dilanjutkan dengan proses pengolahan data menggunakan ArcGis 10.3 untuk melakukan overlay peta serta menghapus data vector yang tidak perlukan. Kemudian di analsisi menggunakan Software DSAS 4.3 untuk menghitung jarak perubahan garis pantai. Prinsip kerja dari penggunaan DSAS ini yaitu menggunakan titik-titik hasil dari perpotongan antara garis transek yang dibuat dengan garis pantai dan berdasarkan waktu sebagai acuan dalam pengukuran (Istiqomah dkk, 2016). 


\section{HASIL DAN PEMBAHASAN}

\section{Perubahan Garis Pantai Tahun 2006-2010}

Perubahan garis pantai di Kota Makassar berdasarkan hasil deteksi dan analisis perubahan garis pantai berdasarkan Digital Shoreline Analisis Sistem (DSAS) telah mengalami perubahan garis pantai pada daerah tertentu di Kecamatan Kota Makassar selama kurun waktu tahun 2006 hingga 2010 beserta hasil cek lapangan pada tahun 2019 dapat dilihat pada Gambar 1. Melihat dari peta perubahan garis pantai tahun 2006-2010 diatas, diperoleh panjang perubahan garis pantai pada setiap Kecamatan dengan menggunakan perhitungan Digital Shoreline Analysis System (DSAS) di Kota Makassar seperti ditunjukkan pada tabel 2.

Kecamatan Biringkanaya memiliki perubahan garis pantai akresi/sedimentasi paling panjang yaitu 199,11 meter/tahun dari perubahan yang terjadi di sepanjang pesisir Biringkanaya. Proses penambahan daratan ini terjadi karena program pemerintahan Kota Makassar yang ingin membuat pulau yang saat ini di sebut Pulau Kolokoloang.

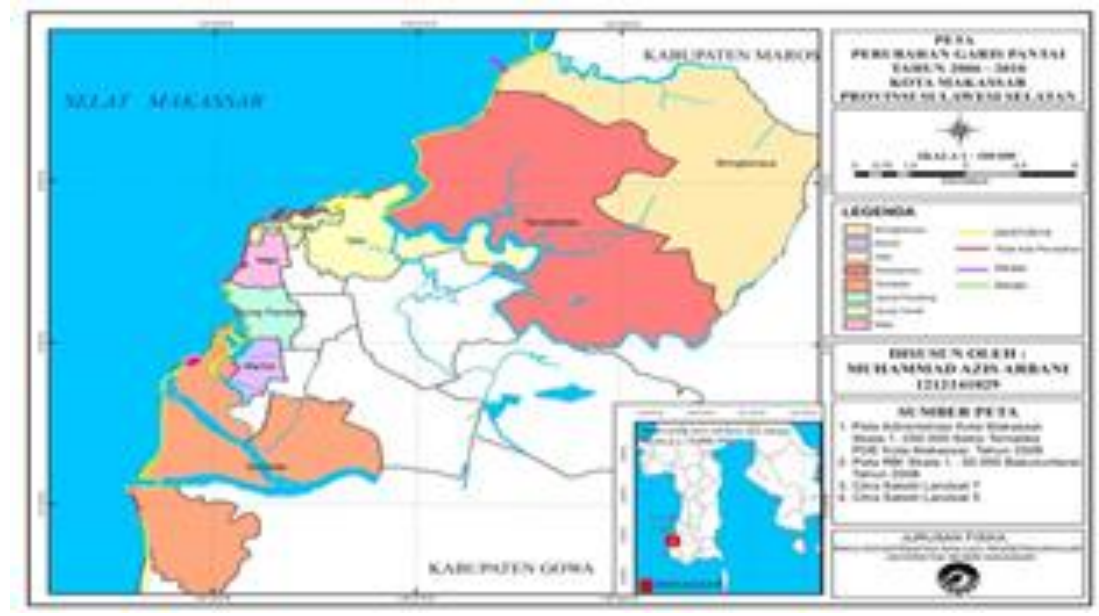

Gambar 1. Peta Perubahan Garis Pantai Kota Makassar Tahun 2006-2010

Tabel 2. Hasil Analisis Nilai NSM Tertinggi Perubahan Garis Pantai Kota Makassar tahun 2006-2010

\begin{tabular}{lcc}
\hline \multirow{2}{*}{ KECAMATAN } & \multicolumn{2}{c}{ NSM(meter/tahun) } \\
\cline { 2 - 3 } & Akresi Tertinggi & Abrasi tertinggi \\
\hline BIRINGKANAYA & 199,11 & - \\
TAMALANREA & 53,97 & 59,58 \\
TALLO & 157,98 & - \\
UJUNG TANAH & - & - \\
WAJO & - & - \\
UJUNG PANDANG & 65,87 & - \\
MARISO & 321,14 & - \\
TAMALATE & 267,10 & 124,17 \\
\hline
\end{tabular}


Kecamatan Tamalanrea mengalami perubahan akresi dan perubahan abarasi. Perubahan akresi paling panjang yaitu 53,97 meter/tahun sedangakan peruabahan akresi paling panjang yang mengalami kemunduran yaitu 59,58 meter/tahun. Perubahan akresi ini disebabkan oleh dinamika laut dimana proses pasang surut, gelombang laut, arus laut dan kecepatan angin yang menyebabkan bibir pantai mengalami pemindahan materi berupa pasir dan tanah dari tempat lain dan memadat di wilayah Tamalanrea. Sementara perubahan abrasi yang terjadi di Kecaamatan Tamalanrea akibat longsornya tanah yang ada di muara sungai Tallo.

Kecamatan Tallo didapat perubahan yang terjadi pada pesisir pantai yaitu perubahan akresi pantai. Panjang perubahan garis pantai yang tertinggi yaitu 157,98 meter/tahun. Sama halnya dengan perubahan yang terjadi di Kecamatan Biringkanaya, pada daerah ini perubahan akresi disebabkan reklamasi pembangunan Makassar New Port. Kecamatan Ujung Pandang perubahan garis pantai yang didapatkan berupa akresi. Panjang perubahan maju akresi tertinggi yang didapatkan yaitu 65,87 meter/tahun. Perubahan ini terjadi karena penimbunan di area bibir anjungan pantai losari guna memperluas area anjungan Pantai losari yang saat ini digunakan sebagai tempat wisata.

Kecamatan Mariso mengalami penambahan daratan atau akresi, dimana perubahan dikarenakan penimbunan guna pembangunan jembatan untuk mempelancar distribusi material yang pada saat digunkan untuk membangun Central Point Indonesia ( $\mathrm{CPI}$ ) dimana dari hasil analisis didapatkan perubahannya yaitu 321,14 meter/tahun. Kecamatan Tamalate juga mengalami perubahan garis pantai akresi dengan perubahan akresi tertinggi yaitu 267,10 meter/tahun. Perubahan akresi tertinggi ini disebabkan penimbunan tanah untuk penambahan pembangunan bangunan Trans Studio. Sedangkan abrasi yang tejadi pada daerah pengamatan ini mengalami perubahan tertinggi 124,17 meter/tahun. Perubahan abrasi akibat pengerukan di bibir pantai untuk memperindah tata lahan pembangunan di area Trans Studio. Kecamatan Ujung Tanah dan Kecematan Wajo tidak ditemukan mengalami perubahan garis pantai, ini dikarenakan pada pesisir pantai telah dilakukan pembangunan secara permanen sehingga tidak menglamani perubahan garis pantai.

\section{Perubahan Garis Pantai Tahun 2010-2013}

Pada hasil pengamatan perubahan garis pantai tahun 2010-2013 diperoleh panjang perubahan garis pantai berdasarkan perhitungan analisis Digital Shoreline Analysis System (DSAS) di Kota Makassar seperti ditunjukkan pada tabel berikut : 
Tabel 3. Hasil Analisis Nilai NSM Tertinggi Perubahan Garis Pantai Kota Makassar Tahun 2010-2013

\begin{tabular}{lcc}
\hline \multirow{2}{*}{ KECAMATAN } & \multicolumn{2}{c}{ NSM(meter/tahun) } \\
\cline { 2 - 3 } & Akresi Tertinggi & Abrasi tertinggi \\
\hline BIRINGKANAYA & 412,42 & 64,32 \\
TAMALANREA & 82,99 & 38,06 \\
TALLO & 375,36 & 130,62 \\
UJUNG TANAH & - & - \\
WAJO & - & - \\
UJUNG & 110,77 & - \\
PANDANG & 76,26 & - \\
MARISO & 719,91 & 75,96 \\
TAMALATE & & \\
\hline
\end{tabular}

Hasil pengamatan menggunakan landat 5 dan landsat 8 hasil overlay didapatkan peta perubahan garis pantai pada tahun 2010-2013. Perubahan garis yang terjadi lebih didominasi akbiat pembangunan sarana prasarana penunjang perekonomian di Kota Makssar. Pembangunan Kota Makassar ini lebih banyak melakukan pemanfaat reklamasi pantai untuk, akibat reklamasi ini wilayah laut mengalami pengurangan bisa diliat pada Gambar 2. Kecamatan Biringkanaya dari hasil pengamatan diperoleh perubahan akresi tertinggi yaitu 412,42 meter/tahun. Perubahan ini adalah kelanjutan dari pembangunan pembuatan Pulau Kolokoloang di Pelabuhan Untia. Sedangakan pada perubahan abarasi yang terjadi akibat perpindahan material yang terjadi dari Sungai Patt'ene Sudiang. Hasil analisis perubahan abrasi yang didapatkan dari pengukuran DSAS bahwa nilai tertinggi yaitu 64,32 meter/tahun.

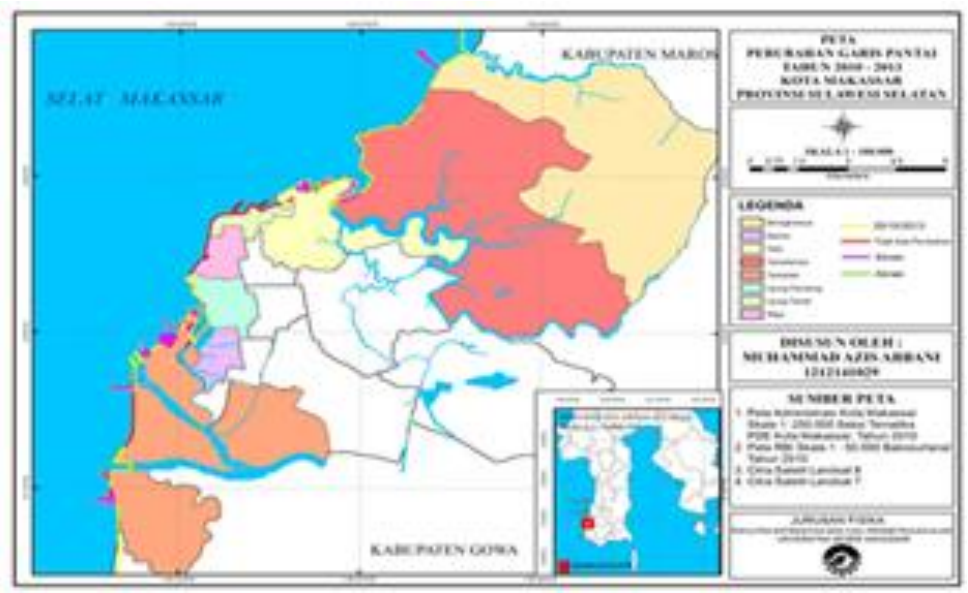

Gambar 2. Peta Perubahan Garis Pantai Kota Makassar Tahun 2010-2013 
Kecamatan Tamalanrea memiliki panjang abrasi tertinggi 82,99 meter/tahun. Kebalikan dari pengamatan sebelumnya yang terjadi abrasi, hasil pengamatan kali ini memperlihatkan terjadinya akresi pada mauara Sungai Tallo. Hal ini akibat penimbunan di area tersebut, penimbunan ini di lakukan untuk penambahan lahan untuk wilayah pergudangan. Sedangkan abrasi yang terjadi dari pengamatan ini dengan nilai tertinggi 38,06 meter/tahun diakibatkan dari terjangan ombak akibat kecepatan angin yang terus menerus mengikis bibir pantai.

Kecamatan Tallo dari hasil pengamatan mengalami akresi dengan perubahan tertinggi yaitu 375,36 meter/tahun. Terjadinya penambahan daratan ini dikarenakan reklamasi yang dilakukan untuk penempatan Gudang Sandal Sancu Makassar. Sedangkan perubahan abrasi dengan nilai perubahan tertinggi 130,62 meter/tahun yang terjadi di wilayah ini akbiat dari pengerukan tanah yang kemudian ditransfer ke area penimbunan rekalamasi Sandal Sancu Makassar juga untuk penaan ruangan yang telah ditentukan sebelum pembangunan. Kecamatan Ujung Pandang terjadi perubahan akresi dengan nilai tertinggi 110,77 meter/tahun. Kemajuan akresi ini diakibatkan penambahan rekonstruksi Pantai Losari yang diperluas ke arah laut. Penambahan ini nantinya diperuntukan agar wisata yang datang ke Makassar semakin bertambah. Area yang di rekalamasi juga berada didepan Fort Rotterdam Makassar yaitu Cafe dan Resto Ombak.

Kecamatan Tallo mengalami penambahan daratan akibat rekalamasi pantai memasuki tahap penimbunan area pantai secara besar-besaran. Area Jembatan Central Poin of Indonesia ini juga dilakukan penimbunan sesuai perencanaan yang telah dilakukan pihak pengelola CPI. Area ini mengalami pertambahan tertinggi 76,26 meter/tahun. Kecamatan Tamalate menjadikan wilayah ini juga mengalami penambahan daratan kearah laut. Panjang akresi tertinggi yang didapatkan dari hasil pengamatan yaitu 719,91 meter/tahun. Sedangkan abrasi yang terjadi di daerah ini berada di Pantai Tanjung Layar Putih dengan nilai abarasi tertinggi yaitu 75,96 meter/tahun

\section{Perubahan Garis Pantai Tahun 2013-2018}

Pada tahun antara 2013 hinga tahun 2018 merupakan periode dimana Kota Makassar menjadi salah satu kota di Negara Indonesia yang mengalami pertumbuhan ekonomi yang sangat cepat, itu dilihat dari struktur bangunan yang telah berkembang dengan cepatnya. Perubahan garis pantai di Kota Makassar tahun 2013-2018 dapat dilihat pada Gambar 3 berikut:

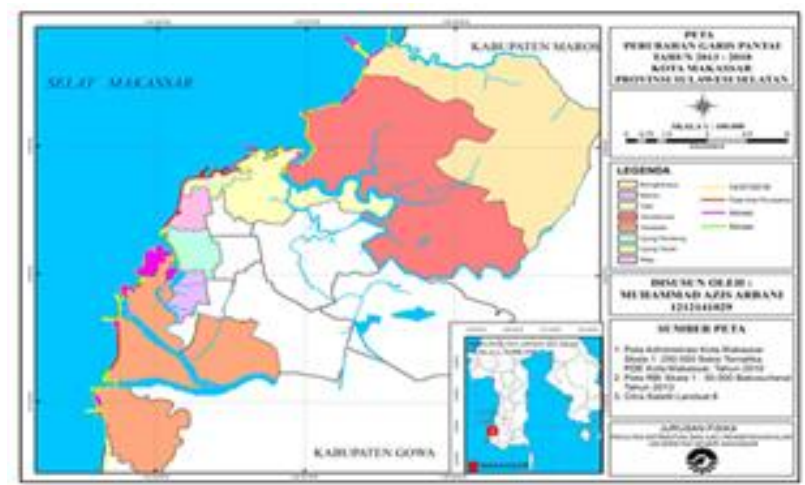

Gambar 2. Peta perubahan garis pantai Kota Makassar tahun 2013-2018 
Dari hasil perhitungan DSAS kita dapat melihat kemajuan dan kemundur garis pantai yang terjadi pada Kota Makassar pada table 4 sebagai berikut :

Tabel 4. Hasil analisis nilai NSM tertinggi perubahan garis pantai Kota Makassar tahun 2013-2018

\begin{tabular}{lcc}
\hline \multirow{2}{*}{ KECAMATAN } & \multicolumn{2}{c}{ NSM(meter/tahun) } \\
\cline { 2 - 3 } & Akresi Tertinggi & Abrasi tertinggi \\
\hline BIRINGKANAYA & 381,45 & - \\
TAMALANREA & 37,32 & 39,14 \\
TALLO & 2351,00 & - \\
UJUNG TANAH & - & - \\
WAJO & - & - \\
UJUNG & 163,23 & 162,03 \\
PANDANG & 0,00 & - \\
MARISO & 802,31 & 232,83 \\
TAMALATE &
\end{tabular}

Dari tabel diatas menunjukkan Kecamatan Biringkanaya mengalami kemajuan atau penambahan daratan. Penambahan ini akibat dari penambahan pembangunan untuk pembuatan Dermaga PPN Untia di Biringkanaya. Penambahan daratan tertinggi yaitu 381,45 meter/tahun. Kecamatan Tamalanrea dari hasil tabel 4 menujukkan terjadinya akresi abrasi, dimana perubahan akresi tertinggi yaitu 37,32 meter/tahun. Perubahan abrasi yang terjadi disepajang pesisir wilayah Tamalanrea adalah penyebab perubahan ini akibat perpindahan materian dikarenakan ombak pantai yang terus menghantam bibir pantai. Sedangakan nilai tertinggi abrasi yaitu 39,14 meter/tahun.

Kecamatan Tallo dimana perubahan akresi paling terlihat ada pada daerah Makassar New Port yang sudah dalam tahap penyelesaian pembangunan. Perencanaan penimbunan pada area ini sudah ditahap akhir dimana sdh tidak ada lagi penimbunan yang dilaksanakan. Nilai perubahan abrasi tertinggi yang diperoleh yaitu 2351,00 meter/tahun. Kecamatan Ujung Pandang, dimana akresi dan abrasi dapat ditemukan pada wilayah pesisir pantai. Nilai tertinggi perubahan abrasi pada wilayah Ujung Pandang yaitu 163,23 meter/tahun. Perubahan ini terjadi akibat kelanjutan pembangunan anjungan Pantai Losari serta penambahan area tempat kapal bersandar di depan Fort Rotterdam Makassar. Sedangkan perubahan abarasi yang terjadi di wilayah ini akibat pengerukan tanah sebagai bentuk penataan ruang yang telah dilakukan pemerintah Kota Makassar. Dimana perubahan abrasi tertinggi di wilayah ini yaitu 162,03 meter/tahun. Untuk periode tahun ini pada Kecamatan Mariso sudah tidak lagi mengalami perubahan garis pantai disepanjang pesisir pantai Kecamatan Mariso sudah dibangun bangunan yang bersifat permanen 


\section{KESIMPULAN}

Berdasarkan hasil penelitian yang telah dilakukan dapat disimpulkan bahwa dalam kurun waktu 12 tahun (2006-2018) pesisir pantai Kota Makassar mengalami dinamika perubahan garis pantai maju dan dinamika perubahan garis pantai mundur pada di 6 daerah Kecamatan anataranya Kecamatan Biringkanaya, Kecamatan Tamalanrea, Kecamatan Tallo, Kecamatan Mariso, Kecamatan Ujung Pandang dan Kecamatan Tamalate. Perubahan garis pantai yang terjadi di Kota Makassar terjadi akibat faktor dari alam dan juga faktor dari manusia. Perubahan yang sangat terlihat untuk saat ini di Kota Makassar berupa akresi (penambahan daratan) yang diakibatkan oleh reklamasi pantai yakni pembuatan bangunan Central Point Indonesia ( $\mathrm{CPI}$ ) di pesisir Kecamatan Tamalate dan pembuatan Makassar New Port di Kecamatan Tallo.

Kecamatan Tamalate juga mengalami pertambahan wilayah daratan kearah laut, dimana perubahan abrasi tertinggi yaitu 802,31 meter/tahun. Tahap pembangunan Central Point of Indonesia ini sudah melalui tahap akhir, dimana saat ini kita sudah bisa liat adanya pembangunan Masjid 99 kubah. Sementara perubahan abrasi yang terjadi diwilayah ini akibat penataan ruang agar bentuk dari Central Point of Indonesia ini memiliki bentuk seperti burung garuda. Nilai tertinggi perubahan abrasinya yaitu 232,83 meter/tahun.

\section{DAFTAR PUSTAKA}

Hakim, A., Sutikno, S., \& Fauzi, M. (2014). J. Sains Dan Teknol. Analisis Laju Perubahan abrasi Pantai Pulau Rangsang di Kabupaten Kepulauan Meranti dengan Menggunakan Data Satelit, 13.

Istiqomah, F., Sasmito, B., Amarrohman, F.J., 2016. Pemantauan Perubahan Garis Pantai Menggunakan Aplikasi Digital Shoreline Analysis System (DSAS) Studi Kasus: Pesisir Kabupaten Demak. J. Geod. Undip 5, 78-89.

Winarso, G., Judijanto, Budhiman, S., 2001. The Potential Application Remote Sensing Data for Coastal Study. Presented at the 22nd Asian Confrence on Remote Sensing, Singapore, pp. 1-5.

Triatmodjo, B. (1999). Teknik Pantai. Yogyakarta: Jurusan Teknik Sipil Fakultas Teknik. Gajah Mada University Press.

Triatmodjo, B. (2011). Perencanaan Bangunan Pantai. Yogyakarta: Betta Offest. 